\title{
Rasa Lokal Rejeki Internasional: "Betul, Betul, Betul" Aspek Ekonomi Politik dalam Kartun Animasi Upin \& Ipin
}

\author{
A. Ranggabumi Nuswantoro, S.Sos. \\ Fakultas Ilmu Sosial dan Ilmu Politik \\ Universitas Atma Jaya Yogyakarta
}

\begin{abstract}
Abstrak
Political economy of media Salah satu hal yang menarik untuk dikaji dari sebuah tayangan televisi adalah aspek ekonomi politik. Aspek tersebut menuntun kita untuk mengetahui esensi dan latar belakang sebuah program, strategi pengembangan bisnis, dan muatan kepentingan politiknya. Ekonomi politik menyingkap fakta-fakta yang sering disembunyikan oleh media kepada publik. Padahal sebagai good consumer dan good citizen, publik berhak mengetahui seluk beluk media berikut aspek ekonomi politiknya. Upin \& Ipin sebagai kartun animasi unggulan Malaysia memiliki muatan ekonomi politik yang sangat besar. Mulai dari kepentingan identitas kewargaan, etnisitas, keuntungan materi, hingga infiltrasi budaya ke negara lain. Upin \& Ipin berhasil menerapkan konsep komodifikasi, spasialisasi, dan strukturisasi dengan baik berbasis lokalitas dan multikulturalisme Malaysia. Upin \& Ipin telah menjadi satu kekuatan animasi yang riil, berpengaruh tidak hanya bagi Malaysia tetapi juga negara-negara tetangga.
\end{abstract}

Keywords: Animation cartoon, etnicity, multicullturalism, political economy of media.

\begin{abstract}
$T V$ program is value laden. There were backgrounds, business strategy, political interest, etc which is called Political Economy of Media. Analysis to Political economy of media will show the facts/interest behind the program. In the other side, public has right to know and to inform the information clearly even the background. Upin \& Ipin is popular cartoon animation for Malaysian even Indonesian. It is value laden of civics, ethnicity, capital and also culture infiltration. Upin \& Ipin apply the concept of commodification, spasialization and structurazion successfully based on Malaysia value. Upin \& Ipin is the real strength not only to Malaysia even the near country.
\end{abstract}

Kata kunci: tayangan kartun animasi, etnisitas, multikulturalisme, dan aspek ekonomi politik media.

\section{Pendahuluan}

Upin \& Ipin adalah kartun animasi yang diciptakan oleh Nizam Abdul Razak, Mohd. Safwan Abdul Karim, dan Usamah Zaid. Ketiganya merupakan bekas mahasiswa dari Multimedia University Malaysia. Awalnya mereka bekerja di sebuah organisasi animasi sebelum akhirnya bertemu dengan bekas pedagang minyak dan gas, Haji
Burhanuddin Radzi dan istrinya Hj. Ainon Ariff pada tahun 2005. Dari pertemuan itu mereka membuka organisasi Les'Copaque. Awalnya karakter Upin \& Ipin dibuat untuk keperluan pembuatan film berjudul Geng: Pengembaraan Bermula. Namun karena dirasa lebih menjanjikan, maka karakter tersebut dipakai tersendiri dalam sebuah serial animasi. 
Upin \& Ipin menarik untuk dikaji karena memberikan perspektif ekonomi politik yang luas, khususnya dalam tayangan animasi anak. Pertama, Upin \& Ipin menampilkan berbagai macam karakter yang mewakili keberagaman di Malaysia, serta mengusung berbagai macam cerita yang mengusung citarasa lokal dan semangat multikultur. Isu multikultur sendiri telah menjadi isu politik yang hangat di Malaysia, terutama setelah diguncang kerusuhan etnis di tahun 2007-2008. Kedua, komodifikasi, spasialisasi, dan strukturasinya menyeruak dengan kuat di sela-sela aktivitas penayangan serial Upin \& Ipin di seluruh penjuru Malaysia dan dunia.

Permasalahannya adalah bagaimana Upin \& Ipin memaksimalkan laba dengan melakukan komodifikasi isi serta audiens, juga menerapkan konsep spasialisasi dan strukturisasi dalam memupuk semangat Satu Malaysia? Tulisan ini menawarkan wacana penelitian yang akan membuka Upin \& Ipin dengan menggunakan teori ekonomi politik media Vincent Mosco

\section{Malaysia: Sengketa Etnis dan Problem Kewarganegaraan}

Malaysia, pada 1998 jumlah penduduknya mencapai 22,2 juta jiwa. Mayoritas terdiri dari orang-orang yang dianggap sebagai penduduk asli atau pribumi, yang dalam bahasa Melayu dikenal dengan nama bumiputera. Jumlah mereka pada saat itu mencapai 57,8\% dari populasi total. Jumlah berikutnya adalah etnis Cina (24,9\%), India (7,0\%), dan lainlain $(3,1 \%)$.

Di awal abad ke-21, komposisi penduduk Malaysia nampaknya tetap sama. Dalam kurun waktu satu dekade tersebut tidak terjadi perubahan berarti dalam komposisi penduduknya.
Penduduk Malaysia pada Februari 2007 sebanyak 26,6 juta terdiri dari $62 \%$ bumiputera (Melayu), 24\% Tionghoa, 8\% India, dengan sedikit minoritas dan suku asli (Departemen Statistik Malaysia). Sedangkan dari sisi agama hampir 60,4\% penduduk memeluk agama Islam; 19,2\% Buddha; 9,1\% Kristen; 6,3\% Hindu; dan 2,6\% Agama Tionghoa tradisional. Sisanya dianggap memeluk agama lain, misalnya Animisme, Agama rakyat, Sikh, dan keyakinan lain; sedangkan 1,1\% dilaporkan tidak beragama atau tidak memberikan informasi.

Sebagaimana terjadi di Indonesia, keberagaman identitas pribumi dan non-pribumi memicu sentimen primordialisme, yang akhirnya menimbulkan serangkaian kejadiankejadian diskriminasi etnis. Perlu diketahui bahwa dalam Konstitusi Malaysia, etnis Melayu ditempatkan sebagai etnis utama dengan Islam sebagai agama negara. Dasar hukum inilah yang membuat seolah-olah sah menempatkan kedudukan etnis Melayu di atas etnis yang lain, serta agama Islam di atas agama lain.

\section{Setelah merdeka, kewarganegaraan yang berkembang di Malaysia adalah sebuah kewarganegaraan yang dibeda-bedakan secara asimetris, yang memberikan hak- hak dasar warga negara pada orang- orang Cina dan India dengan imbalan hak-hak istimewa dalam bidang hukum, politik, dan ekonomi pada orang-orang Melayu. Dominasi budaya ada pada etnis Melayu, termasuk juga agamanya -Islam- yang ditetapkan sebagai agama negara (Hefner, 2001: 56).}

Hal tersebut tercermin antara lain lewat kebijakan ekonomi baru Malaysia (National Economy Policy) yang dilansir pada tahun 1971-1990. Kebijakan yang berideologi developmentalis tersebut menyatakan, intinya, pemerintah 
mendorong tumbuhnya kegiatan ekonomi dengan cara meningkatkan industrialisasi dan modernisasi di Malaysia. Pembangunan berperspektif kapitalisme diprioritaskan oleh pemerintah Malaysia dan ekspansi bisnis dari luar diperluas. Perekonomian Malaysia ditopang oleh investasi dan pembangunan infrastruktur.

Cara yang ditempuh Malaysia ini menekankan pada pertumbuhan ekonomi yang ditentukan oleh tingginya tabungan dan investasi (HarrodDomar, dalam Budiman, 1996: 19).

Sepintas tidak ada yang salah, atau janggal dari kebijakan ekonomi baru tersebut. Namun ternyata kebijakan tersebut menjadi alat bagi penguasa untuk meningkatkan nasionalisme Malaysia tetapi dengan cara yang tidak terpuji, yakni memberikan hak istimewa kepada etnis utama di Malaysia -etnis Melayu- dan mengorbankan etnis lain.

Kebijakan ekonomi baru menjadi cara bagi pemerintah untuk mengatasi kesenjangan antara minoritas Tionghoa dan mayoritas Melayu (Tay, 2011: 3).

Perlu diketahui di masa-masa awal Malaysia merdeka yang menguasai sentra ekonomi Malaysia adalah etnis Tionghoa. Kelas menengah atas pada waktu itu dikuasai oleh orang-orang Tionghoa. Mereka berkedudukan sebagai manajer dan pekerja professional yang memenuhi seantero negeri. Dengan kebijakan ekonomi yang baru, pemerintah ingin menciptakan kemakmuran ekonomi di etnis Melayu, yang merupakan etnis utama dan terbesar di Malaysia.

Usaha pemerintah Malaysia berhasil. Tidak lama setelah Kebijakan Ekonomi Baru dilansir kelas menengah baru tumbuh, yakni mereka yang berasal dari etnis Melayu. Sisi lain positif karena perekonomian Malaysia membaik. Namun sisi lain kebijakan tersebut menyisakan aroma diskriminasi yang luar biasa, khususnya kepada etnis Tionghoa dan India. Mereka melihat pemerintah Malaysia memprioritaskan etnis Melayu untuk berkembang, sedangkan tidak bagi etnis yang lain.

Etnis India misalnya, tidak mendapatkan tempat yang layak dalam kebijakan tersebut, termasuk kebijakan di bidang pendidikan. Anak-anak India masih sulit mengakses pendidikan di Malaysia (Embong, 2001: 131).

Selain itu gerakan ekonomi baru juga menginisiasi munculnya gerakan-gerakan kebangkitan Islam (yang disponsori oleh pengusaha-pengusaha Melayu bekerja sama dengan pemerintah). Gerakan tersebut mengganjal interaksi inter etnis dan inter religius yang sebenarnya mulai berjalan baik di Malaysia.

Kenyataan-kenyataan di atas menunjukkan bahwa Malaysia sebagai sebuah negara memiliki problem etnis dan kewarganegaraan yang serius. Walaupun usaha-usaha mewujudkan kedamaian warga berbasis pluralisme terus-menerus dilakukan, namun tampaknya bara persoalan etnis masih terus ada dan menyala di Malaysia. Terbukti November 2007 lalu, sebagaimana keterangan yang diberikan oleh Hindu Right Action Force (Hindraf), warga etnis India di Malaysia menggelar aksi protes anti pemerintah terbesar sepanjang sejarah Malaysia. Lebih dari 10.000 orang terlibat dalam aksi unjuk rasa untuk menyuarakan keluhan diskriminasi ras tersebut, tanpa menghiraukan tembakan meriam air dan gas air mata. Aksi protes skala besar yang diadakan sebuah kelompok pembela hak asasi kaum Hindu itu menjadi tantangan politik bagi pemerintah yang pada waktu itu berencana menyambut 
pemilihan umum. Waktu itu masyarakat etnis India dari seluruh penjuru Malaysia berkumpul di Kuala Lumpur untuk melakukan unjuk rasa, meski kawasan ibukota telah ditutup selama tiga hari terakhir, sementara pemerintah dan polisi telah mengeluarkan peringatan agar masyarakat tidak terlibat. Mereka merasa frustasi dan tidak memiliki kesempatan bekerja di pemerintahan atau pun di sektor swasta. Mereka tidak diberikan izin usaha atau pun kursi di perguruan tinggi. Selain itu warga etnis India juga merasa marah akibat penggusuran beberapa kuil Hindu yang dilakukan pemerintah Malaysia.

Tidaklah mengherankan jika seorang Malaysianis, Timothy P. Daniels, menyatakan bahwa setelah lebih dari empat puluh tahun dari kemerdekaan politik, Malaysia masih menyala dengan sentimen nasionalis dan kerinduan akan kerukunan berbasis pluralisme (2005: 23). Dalam setiap perayaan kenegaraan, baik hari kemerdekaan maupun hari Malaysia, kerinduan tersebut selalu muncul. Malaysia senantiasa mengungkapkan keinginannya untuk menciptakan satu masyarakat besar yang bersatu, adil, makmur, dan sejahtera.

\section{Multikulturalisme Malaysia Sebagai Komoditas}

Sebagai negara dan bangsa yang multikultur, Malaysia menyadari betul bahwa mereka musti punya produk budaya yang disukai dan menggambarkan keragaman etnis, budaya, dan agama. Singkatnya Malaysia belum memiliki produk budaya yang populer dan bisa merepresentasikan kemalaysiaan mereka. Puluhan tahun berjalan nampaknya usaha tersebut belum berhasil. Kebudayaan Malaysia masih tampak sebagai kebudayaan yang bersifat geografis. Artinya segala bentuk budaya dicatat dan didaftar oleh pemerintah Malaysia. Hal inilah yang sempat menimbulkan masalah dengan Indonesia, ketika pemerintah Malaysia mengklaim beberapa budaya menjadi miliknya tanpa memperhatikan unsur historis-filosofis budaya tersebut, yang ternyata berakar di Indonesia. Sebagaimana diungkap dalam website kantor berita Antara, Wakil Menteri Pendidikan dan Kebudayaan, Windu Nuryanti, membentang catatan klaim Malaysia atas kekayaan budaya asli Indonesia selama ini. Pada rentang 20072012,Malaysiasudahtujuhkalimengklaim budaya Indonesia sebagai warisan budaya mereka. Nuryanti menyatakan bahwa sejarah klaim Malaysia cukup panjang, dalam catatannya Malaysia sudah mengklaim budaya Indonesia sebagai budayanya sebanyak tujuh kali. Statement Nuryanti tersebut, waktu itu, juga menjadi statement perdana seorang pejabat negara Indonesia menyatakan perihal klaim budaya oleh Malaysia itu kepada publik.

Nuryanti mengurai bahwa klaim Malaysia itu bermula pada November 2007 terhadap kesenian reog ponorogo, selanjutnya pada Desember 2008 klaim atas lagu Rasa Sayange dari Kepulauan Maluku. Lalu klaim batik pada Januari 2009. Tari pendet yang jelas-jelas dari Bali juga diklaim Malaysia pada Agustus 2009 yang muncul dalam iklan pariwisata negeri jiran yang suka menyatakan diri sebagai The Truly Asia itu. Selanjutnya instrumen dan ansambel musik angklung pada Maret 2010. Tidak hanya seputar tari saja, Malaysia juga masuk dalam ranah budaya kuliner. Beras asli Nunukan, Kalimantan Timur, yaitu beras Adan Krayan, diklaim menjadi milik Malaysia dan dijual dengan merk Bario 
Rice. Terakhir yang terbaru adalah klaim Malaysia atas tari tor-tor dan gondang sambilan yang merupakan asli kesenian dari Sumatera Utara.

Walau akhirnya segala klaim tersebut terpatahkan, namun tindakan pemerintah Malaysia tersebut semakin menunjukkan kegelisahan mereka atas ketiadaan produk budaya yang mencerminkan diri mereka sebenar-benarnya. Usaha budaya yang dilakukan oleh masyarakat Malaysia sebenarnya tidak pernah kurang, atau surut. Sejak tahun 1970-an beberapa kartunis Malaysia mencoba mengembangkan karakter-karakter yang merepresentaskan Malaysia. Sebut saja kelahiran majalah kartun seperi $\mathrm{Ha}$ $\mathrm{Hu}$ Hum (Rejabhad), Jenakarama, Wak Dojer. Tahun 1980 sampai era 1990-an terbit majalah kartun Bujal dan Bambino. Majalah-majalah tersebut menyajikan karakter dan cerita yang asli Malaysia. Namun tampaknya produk tersebut belum mampu unjuk gigi di kancah dunia popular Malaysia. Tidak terlalu digemari oleh masyarakat Malaysia, terutama anak-anak, akibatnya perkembangannya juga timbul tenggelam.

Kenyataan ini nampaknya disadari benar oleh Les'Copaque sebagai produsen Upin \& Ipin. Les'Copaque sadar bahwa multikulturalisme menjadi isu hangat di Malaysia. Maka, Upin \& Ipin dipikirkan, dirancang, dan dibuat untuk masuk dalam kekosongan tersebut. Upin \& ipin mengalami komodifikasi isi dengan menguatkan unsur-unsur kebudayaan Malaysia di dalam ceritanya.

Walau demikian Upin E Ipin sekaligus juga penegasan bahwa walaupun beragam, multietnis, multireligius, namun dominasi budaya dan agama tetap dipegang oleh Melayu dan Islam (Embong, 2001 dalam Hefner, 2001: 141-142).
Kekuatan karakter menjadi salah satu unggulan Upin \& Ipin. Berbagai macam karakter hadir di sini, mewakili keragaman Malaysia di satu sisi sekaligus menampung ide komodifikasi di sisi lain. Karakter-karakter tersebut hadir dalam balutan cerita yang bercitarasa lokal. Menurut Steven Patrick (2008), rasa lokal inilah yang menguatkan posisi Upin \& Ipin dalam percaturan film atau tayangan animasi, khususnya di Malaysia.

Sebagaimana diungkapkan oleh Les'Copaque, Upin dan Ipin merupakan sepasang kakak-beradik kembar berusia belia yang tinggal bersama Kak Ros dan Mak Uda (biasa dipanggil Opah) di Kampung Durian Runtuh setelah kematian kedua orangtua mereka sewaktu masih bayi. Upin dan Ipin bersekolah di Tadika Mesra yang terletak dalam kawasan kampung, di mana mereka berteman dengan banyak teman yang bermacam-macam tingkah lakunya, seperti Mei Mei yang imut dan cerdas, JarjitSingh yang lucu dan gemar membuat pantun, Ehsan yang suka menyendiri, cerewet dan suka makan, Fizi (sepupu Ehsan) yang penuh keyakinan diri tetapi suka mengejek orang lain, dan Mail yang berkemampuan untuk berjualan, suka melamun dan mengantuk.

Jika dicermati semua tokoh atau karakter di atas merepresentasikan keragama Malaysia. Sebutlah Upin, Ipin, Kak Ros, dan Mak Uda merepresentasikan etnis Melayu asli. Artinya mereka dimunculkan sebagai sosok etnis Melayu asli yang sederhana dan masih tinggal di kampung/desa. Hal ini menarik sebab kenyataannya akibat buah dari kebijakan ekonomi baru (NEP) tumbuh kelas menengah Melayu baru, yang tinggal di perkotaan dan berprofesi sebagai pekerja kantoran dan profesional. Romantisme terhadap Melayu asli 
ditampilkan oleh Les'Copaque, dan karakter Upin \& Ipin beserta keluarganya sungguh menggambarkan hal tersebut. Selanjutnya terdapat karakter Jarjit Singh yang beretnis India, lengkap dengan ciriciri fisik tubuh serta gaya bicara yang sungguh menggambarkan keetnisan India. Dalam keterangan Les'Copaque, Jarjit adalah seorang anak-anak laki-laki berketurunan India Punjabi. Usianya sebaya dengan teman-teman sekelasnya, tapi menariknya suara Jarjit dibuat besar seolah-olah sudah dewasa. Seperti kita tahu, etnis India memang memiliki suara yang khas dan berkarakter berat. Jarjit juga dikenali karena kepandaian berjenaka dan berpantunnya, khususnya pantun dua baris yang bermula dengan "Dua tiga". Sebelum Mengatakan “Dua Tiga" Jarjit Selalu Mengatakan Hebat! Hebat! Jarjit sungguh karakter citraan yang sangat ideal bagi etnis India di Malaysia.

Lain lagi dengan Mei Mei. Mei Mei merupakan anak keturunan Cina yang pandai, terampil, dan tekun sekali pemikirannya di kalangan kawan-kawan Upin dan Ipin. Mei Mei adalah anak terpintar di kelasnya. Mei Mei memiliki banyak pengetahuan yang tidak dimiliki anak sebayanya. Lewat karakter Mei Mei ditunjukkan bahwa Malaysia juga memiliki warga berketurunan Cina, yang hidup bersama dan membaur dengan yang lain. Agama Mei Mei bukan Islam melainkan Khonghucu.

Selain Upin \& Ipin beserta temantemannya, masih banyak karakter lain yang hadir yang mewarnai kehidupan sehari-hari Upin \& Ipin. Semuanya memiliki kesamaan, yakni mencerminkan karakter khas masyarakat Malaysia yang multikultur. Satu hal yang luar biasa adalah dimunculkannya karakter Susanti. Susanti merupakan anak perempuan yang berasal dari sebuah keluarga dari Jakarta, Indonesia, baru tinggal di Malaysia dan belum terbiasa dengan obrolan anak-anak lainnya. Pertama kali muncul pada episode "Berpuasa Bersama Kawan Baru". Diceritakan juga di sana bahwa teman Upin \& Ipin, yakni Mail nampaknya diam-diam tertarik dengan Susanti. Susanti sendiri juga muncul di episode "Diri Bersih Badan Sihat", dan "Sapy oh Sapy". Lewat karakter Susanti Les'Copaque mencoba "berkomunikasi" dengan Indonesia. Berkomunikasi di sini bisa berarti banyak hal: Pertama, Susanti hadir sebagai representasi masyarakat Indonesia yang berada di Malaysia. Sudah menjadi informasi umum bahwa tenaga kerja Indonesia menjadi tenaga kerja asing terbanyak di Malaysia. Sebagian besar adalah perempuan dan bekerja di sektor domestik. Mungkin itu juga alasannya yang dimunculkan adalah karakter perempuan, bukan laki-laki. Kedua, Susanti menjadi kunci tayangan Upin \& Ipin untuk masuk semakin dalam ke Indonesia. Upin \& Ipin sangat digemari di Indonesia. Dalam suatu riset rating yang dilakukan oleh AGB Nielsen Research pada newsletter Januari 2010, delapan stasiun TV nasional Indonesia menayangkan animasi anak. Urutan pertama rating diduduki oleh Upin \& Ipin. Bandingkan dengan karakter lokal Unyil yang hanya menempati urutan tujuh. Karakter Susanti seolah-olah menjawab kerisauan beberapa pihak di Indonesia yang mulai menyadari bahwa bagaimanapun Upin \& Ipin bukan karakter asli Indonesia. Susanti mampu meredam itu semua. Buktinya Upin \& Ipin semakin laris dan digemari di Indonesia. Ketiga, karakter Susanti seolah-olah dihadirkan sebagai suatu oase bagi hubungan diplomatik MalaysiaIndonesia yang sempat memburuk di 
pertengahan tahun 2000-an. Karakter Susanti mencoba mencairkan itu semua. Bahwa Malaysia juga menerima sosok Indonesia dengan damai di negeri mereka. Walau belum terukur secara empiris, namun usaha diplomasi Malaysia lewat karakter Susanti ini patut dihargai.

Keberhasilan

Les'Copaque menciptakan karakter-karakter berbasis multikulturalisme Malaysia juga berdampak pada keberhasilan finansial serial Upin \& Ipin. Les'Copaque berhasil menggaet beberapa pengiklan besar untuk masuk dalam Upin \& Ipin. Sebagaimana dinyatakan oleh Vincent Mosco (1996: 129) bahwa komodifikasi adalah perubahan nilai guna menjadi nilai tukar. Keberagaman masyarakat Malaysia, dengan segala unsur budaya yang melekat padanya, dikreasi sedemikian rupa hingga menjadi ceritacerita menarik dalam Upin \& Ipin. Komodifikasi audiens juga muncul dalam Upin \& Ipin, mengiringi komodifikasi isi. Hingga saat ini, Upin \& Ipin berhasil menggaet pengiklan dengan jumlah yang banyak: mulai dari KFC, Proton, Wyeth, hingga TM (Telekom Malaysia). Para pengiklan tersebut hadir di Upin \& Ipin dalam berbagai bentuk, ada yang berupa iklan di website Upin \& Ipin, namun ada juga yang masuk dalam cerita Upin \& Ipin. Seperti pada seri Upin \& Ipin yang berjudul “jalan-jalan”, digambarkan Upin \& Ipin beserta teman-temannya jalanjalan keliling kota dengan menumpang salah satu mobil milik seorang yang bernama Saleh. Bisa ditebak, mobil yang mereka pakai terang-terangan bermerek Proton tipe Exxora. Sungguh suatu kecerdikan yang luar biasa, memadukan kepentingan pengiklan dengan isi cerita.

\section{Upin \& Ipin Merangkul Asia: Dari Kartun Animasi Sampai Ubat Gigi}

Selain usaha komodifikasi yang bisa dibaca dari Upin \& Ipin, Les'Copaque sebagai produsen juga melakukan serangkaian usaha yang bisa kita sebut sebagai usaha spasialisasi, yakni usaha meluaskan bisnis dengan mengatasi ruang dan waktu (Mosco, 1996). Spasialisasi bisa berbentuk vertikal dan horizontal: vertikal ketika perusahaan induk beranakpinak menjadi perusahaan-perusahaan turunan yang memiliki fokus bisnis. Sedangkan horisontal ketika perusahaan induk mengakuisisi atau bekerja sama dengan perusahaan-perusahaan lain di luar dirinya.

Les'Copaque mengawali usaha spasialisasi vertikalnya di tahun 2008 dengan mendirikan secara khusus anak perusahaan yang bernama LCP Animation Training Centre. Lembaga training ini secara khusus menggaet muda-mudi Malaysia untuk bersamasama belajar animasi. Keberhasilan Upin \& Ipin tentu menjadi senjata promosi yang utama. Selanjutnya pada akhir tahun 2008, Les'Copaque mendirikan anak perusahaan yang khusus menangani merchandise serial Upin \& Ipin, yakni LC Merchandising. LC Merchandising menggelar online shop dan memegang lisensi produk Upin \& Ipin di seluruh penjuru dunia. Online shop menjadi cara Les'Copaque mengatasi tantangan ruang dan waktu. Artinya Les'Copaque tidak mau kehilangan potensi finansial dari penggemar Upin \& Ipin di seluruh penjuru dunia (terutama di Asia). Merchandise yang mereka tampilkan dalam online shop dilabeli merchandise asli, bukan bajakan dan tiruan. Les'Copaque mencoba meredam plagiasi merchandise yang dilakukan oleh beberapa usahawan 
lokal di Asia (termasuk Indonesia).

Tahun 2011, bisnis Les'Copaque bergerak ke kuliner dengan mendirikan Geng's Corner Restoran \& Katering. Restorantersebutmenyajikanmenuutama ayam goreng beserta kelengkapannya. Nampaknya Les'Copaque tahu betul bahwa penggemar Upin \& Ipin sebagian besar adalah anak-anak, yang memiliki kegemaran jajan. Oleh karena itu Geng's Corner hadir untuk mewadahi potensi ini. Kabarnya dalam waktu dekat Geng's Corner akan dibuat franchise dan ditawarkan ke seluruh negara Asia yang menayangkan serial Upin \& Ipin.

Les'Copaque memanfaatkan popularitas Upin \& Ipin untuk pengembangan bisnis eksternalnya. Atau dengan kata lain, Les'Copaque juga melakukan serangkaian usaha spasialisasi horizontal. Usaha tersebut dimulai dari masuk ke jaringan disney channel, menerbitkan buku bersama penerbit di berbagai negara, menerbitkan majalah komik Upin \& Ipin, membuat merchandise bersama KFC, memproduksi 'ubat' gigi, hingga menyediakan konten di Apple Store. Di Indonesia, Les'Copaque setidaknya bekerja sama dengan dua perusahaan lokal, yakni PT . Consobiz Ventures dan PT. Danapersadaraya Motor Industry (DMI). Masing-masing untuk membuat popok bayi dan helm SNI Upin \& Ipin! Luar biasa, ekspansi bisnis dilakukan tidak hanya di Malaysia melainkan sampai di negeri tetangga dengan memproduksi barang-barang yang kategori kebutuhannya premium.

\section{Meruntuhkan Dominasi Kartun Jepang}

Sejak kepemimpinan Mahathir Muhamad, Malaysia memimpikan diri menjadi macan asia. Nampaknya mimpi tersebut dilanjutkan dengan baik oleh
Upin \& Ipin. Serial televisi Upin \& Ipin dilebarkan oleh Les'Copaque hingga Indonesia, Singapura, dan Turki. Tahun 2009 secara resmi Upin \& Ipin masuk ke Disney Channel Asia, menjangkau lebih banyak negara di Asia.

Menurut survei yang dilakukan Malaysia News Centre (2008), penonton Upin \& Ipin di Asia telah menandingi jumlah penonton kartun Jepang. Dominasi kartun Jepang di Asia mulai runtuh. Hal ini makin diperkuat manakala Les'Copaque memproduksi seri komik Upin \& Ipin. Mereka pun bekerja sama dengan penerbit-penerbit lokal di berbagai negara. Upin \& Ipin menjadi dominasi tersendiri di Asia. Di Indonesia misalnya, Les'Copaque bekerjasama dengan penerbit lokal yakni penerbit Mizan, dan menerbitkan sekian banyak judul buku Upin \& Ipin. Bukubuku yang ada tidak hanya buku cerita, melainkan juga buku belajar bergambar, buku sholat, sampai buku aktivitas dan mewarnai.

Khusus di dunia buku, Upin \& Ipin tampaknya menginspirasi produsen lain untuk memunculkan cerita-cerita lokal Asia lain. Sebut saja beberapa cerita lokal dari India. Buku komiknya bisa dinikmati oleh anak-anak di Indonesia. Selain itu cerita-cerita lokal Indonesia juga mulai diangkat kembali oleh beberapa penerbit. Cerita-cerita asli daerah misalnya, mulai dimunculkan kembali dengan kualitas gambar dan modifikasi cerita yang menjadikannya lebih menarik. Pada titik ini nampaknya benar jika dikatakan dominasi kartun Jepang mulai runtuh. Anak-anak di Indonesia kini tidak lagi terpaku pada bacaan komik dari Jepang, melainkan mulai melirik cerita-cerita lain yang berbalut cerita lokal dari masingmasing daerah. 


\section{Mimpi Satu Malaysia}

Sebagaimana ditulis dalam sub bab sebelumnya, Malaysia sampai detik ini masih gamang dalam mewujudkan kesatuan negaranya. Salah satunya disebabkan Malaysia tidak memiliki perangkat nasional yang memungkinkan seluruh komponen bangsanya bersatu, seperti halnya Pancasila di Indonesia. Maka dibuatlah '1 Malaysia' atau 'Satu Malaysia' oleh Perdana Menteri Malaysia, Datuk Seri Najib Tun Razak pada 16 September 2008. Inti gagasan ini adalah gagasan satu bangsa tanpa memandang etnis, sub-etnis dan kebudayaan.

Upin \& Ipin adalah kartun animasi yang pertama mewadahi gerakan 'Satu Malaysia' ini. Gerakan tersebut dimunculkan secara terbuka di salah satu episode Upin \& Ipin berjudul "Kami 1 Malaysia". Ini menunjukkan bahwa Upin \& Ipin tidak lepas dari kepentingan strukturasi, yang memunculkan relasi ras, gender, dan agama dalam isi media. Upin \& Ipin dengan sangat baik menggambarkan kegamangan Malaysia dengan memperlihatkan dominasi budaya Melayu dan Islam, namun sekaligus juga ingin memunculkan semangat multikulturalisme.

Usaha Les'Copaque, lewat Upin \& Ipin ini nampaknya selaras dengan teori yang diungkapkan Benedict Anderson (1995) tentang terbentuknya nasionalisme. Anderson mendefinisikan nasion sebagai "an imagined political community" - dan dibayangkan baik terbatas secara inheren maupun berdaulat. Kata "imagined" di sini lebih berarti "Orang-orang yang mendefinisikan diri mereka sebagai anggota suatu nasion, meski mereka tidak pernah mengenal, bertemu, atau bahkan mendengar tentang warga negara yang lain, namun dalam pikiran mereka hidup suatu citra (image) mengenai kesatuan komunion bersama". Upin \& Ipin mencoba membangkitkan imajinasi masyarakat Malaysia, yang multikultur, sebagai satu nasion. Selaras dengan gerakan Satu Malaysia, penciptaan imajinasi ini tampaknya dilakukan dalam usaha yang sistematis dan menggunakan ikon-ikon populer. Upin \& Ipin menjadi salah satu pilihan yang tepat.

\section{Simpulan}

Walau terdapat banyak catatan terhadap Malaysia dan segala kehidupan bermasyarakat dan bernegaranya, namun Upin \& Ipin yang dibesut oleh Les'Copaque menjadi contoh suksesnya media mengeksplorasi unsur-unsur multikulturalisme. Unsur-unsur multikulturalisme tersebut muncul menyeruak dalam aktivitas komodifikasi, spasialisasi, dan strukturasi yang dilakukan Les'Copaque. Bagaimanapun, Upin \& Ipin berhasil mengisi kekosongan tayangan anak yang menampilkan nilainilai positif multikural. Tidak hanya bagi Malaysia namun juga bagi kebanyakan negara di Asia yang penduduknya plural.

\section{Daftar Pustaka}

Anderson, Benedict, 2008, Imagined Communities: Komunitas-Komunitas Terbayang, Yogyakarta: Insist Press.

Budiman, Arief, 1996, Teori Pembangunan Dunia Ketiga, Jakarta: Gramedia.

Calabrese, Andrew \& Colin Sparks, 2004, Toward a Political Economy of Culture: Capitalism and Communication in The Twenty-First Century, Maryland: Rowman \& Littlefield Publishing.

Daniels, Timothy P., 2005, Building Cultural Nationalism in Malaysia, New York: Routledge. 
During, Simon, 1999, The Cultural Studies Reader Second Edition, London and New York: Routledge

Hefner, Robert W, 2001, The Politics of Multiculturalism, Pluralism, and Citizenship in Malaysia, Singapore, and Indonesia, University of Hawai Press

Magnis-Suseno, Franz, 1992, Filsafat Sebagai Ilmu Kritis, Yogyakarta: Kanisius

Mosco, Vincent, 2009, The Political Economy of Communication, London: Sage Publication
Parekh, Bhikhu, 2008, Rethinking Multiculturalism: Keberagaman Budaya dan Teori Politik, Yogyakarta: Kanisius.

Patrick, Steven, Here's the tale behind a local animation powerhouse that's making waves, MSC Malaysia News Centre. Diakses dari http://newscentre. msc.com.my/articles/542/1/ Animating-Malaysia-for-the-world/ Page1.html tanggal 18Oktober 2012

Tay, Eddie, 2011, Colony, Nation, and Globalisation: Not at Home in Singaporean and Malaysian Literature, Hongkong: Hongkong University Press. 